\title{
Direct electrochemical reduction of carbon dioxide by a molybdenum-containing formate dehydrogenase
}

\author{
Cristina M. Cordas *, Mariana Campaniço, Rita Baptista, Luísa B. Maia, Isabel Moura , José J.G. Moura * \\ LAQV, REQUIMTE, Departamento de Química, Faculdade de Ciências e Tecnologia, Universidade Nova de Lisboa (FCT NOVA), 2829-516 Caparica, Portugal
}

\section{A R T I C LE INFO}

\section{Keywords:}

Formate dehydrogenase

Direct electrochemistry

$\mathrm{CO}_{2}$ reduction

Electrocatalysis

\begin{abstract}
A B S T R A C T
Formate dehydrogenase enzymes catalyse the reversible two-electron oxidation of formate to carbon dioxide. The class of metal-dependent formate dehydrogenases comprises prokaryotic enzymes holding redox-active centres and a catalytic site, containing either molybdenum or tungsten ion, that mediates the formate/carbon dioxide interconversion. The carbon dioxide reduction is of a particular interest, since it may be a route for its atmospheric mitigation with the simultaneous production of added-value products, as formate-derived compounds. Recently, the periplasmic formate dehydrogenase from Desulfovibrio desulfuricans, a molybdenum-containing enzyme, was proven to be an efficient enzyme for the $\mathrm{CO}_{2}$ reduction to formate. In this work, the immobilized formate dehydrogenase isolated from Desulfovibrio desulfuricans direct electrochemical behaviour was attained in the presence and absence of substrates and the formal potentials associated with the catalytic centre transitions were determined in non-turnover conditions. The enzyme catalytic activity towards carbon dioxide reduction was observed using direct electrochemical methods.
\end{abstract}

\section{Introduction}

Formate dehydrogenase enzymes (FDHs) are a group of heterogeneous proteins that catalyse the reversible formate $\left(\mathrm{HCOO}^{-}\right)$oxidation to carbon dioxide $\left(\mathrm{CO}_{2}\right)$ (Eq. (1)). These enzymes are classified in two families, one gathering the enzymes that hold no redox-active centres and another that includes all the metal-dependent enzymes [1-3].

The metal-dependent FDHs are found only in prokaryotic organisms and all have in common the presence of one molybdenum or one tungsten ion in the active site coordinated by four sulfur atoms of two pyranopterin cofactors and additional sulfur and/or selenium atoms [4-6]. Both FDH classes have been the subject of intense research, since it was unveiled that the enzymatic reaction can be run reversibly, depending on the experimental conditions, allowing the consumption (reduction) of carbon dioxide with formation of formate (Eq. (1)) [1-3,7-11].

$\mathrm{CO}_{2}+2 \overline{\mathrm{e}}+\mathrm{H}^{+} \rightleftharpoons \mathrm{HCOO}^{-}$

This enzymatic reaction is of great interest since it may contribute to decrease the high atmospheric carbon dioxide levels, converting this green-house gas back into fuel or other added-value chemicals [12,13]. The reaction of formate formation from $\mathrm{CO}_{2}$ is one of the most interest- ing, because of the highest added value when compared with the energy required to form the product [14]. The reaction electrochemical control has been pursuit aiming an integration on bioelectrochemical systems (BES) that would allow the $\mathrm{CO}_{2}$ conversion with (sustainable) low energy consumption, employing mild conditions, to produce a single and specific product - formate (or formic acid) [15]. The feasibility of the utilization of FDHs, in general as catalyst in BES, has already been shown, namely using FDH isolated from Candida boidinii (an enzyme that is NADH-dependent and metal-independent, available commercially) in the electrosynthesis of formate from $\mathrm{CO}_{2}$, although the imposition of a high overpotential was necessary ( $-1 \mathrm{~V}$ vs. $\mathrm{Ag} / \mathrm{AgCl})$ [16]. A decrease in the required overpotential was described with the immobilization of Methylobacterium extorquens ( $\mathrm{Me}$ ) FDH (a tungsten-containing enzyme), through the use of modified carbon-based electrodes with several polymers incorporating mediators [17]. Recently, the co-immobilization of a redox polymer (cobaltocene) together with a molybdenum-containing FDH (isolated from Escherichia coli) allowed the enhancement of the three-dimension matrix and, as so, also the mediated electron transfer rate [18]. The use of direct electrochemical methods to tune the FDH activity has been widely searched [19-22].

Amongst the studies of the viability in using FDH enzymes to catalyse the $\mathrm{CO}_{2}$ reduction, recently, it was found that the periplasmic FDH

\footnotetext{
* Corresponding authors.

Email addresses: cristina.cordas@fct.unl.pt (C.M. Cordas); jose.moura@fct.unl.pt (J.J.G. Moura)
} 

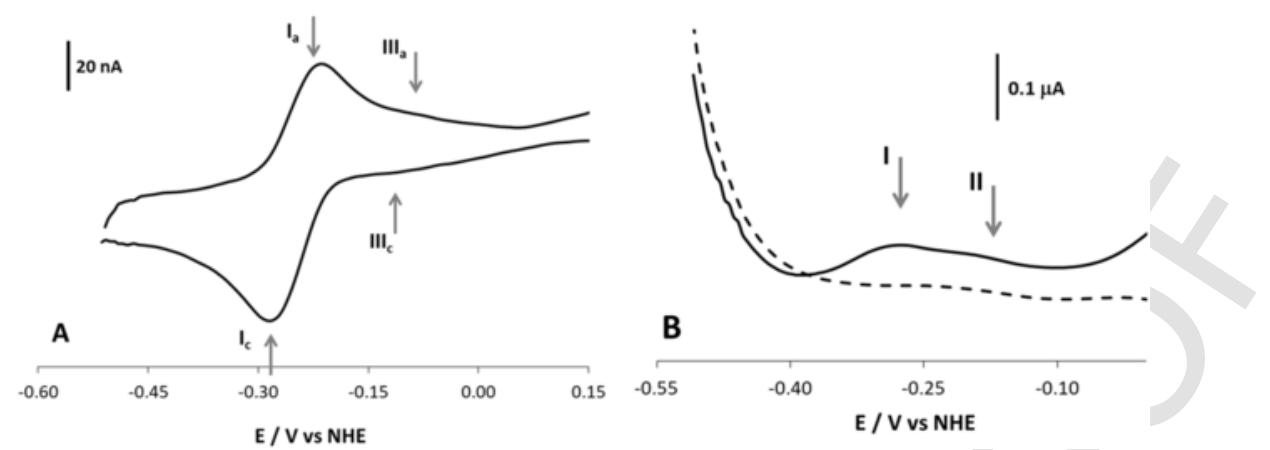

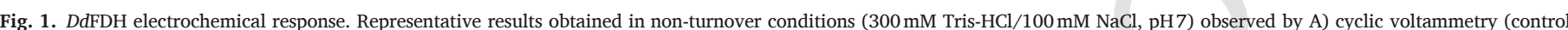

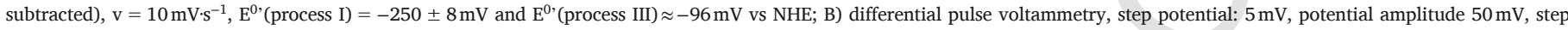

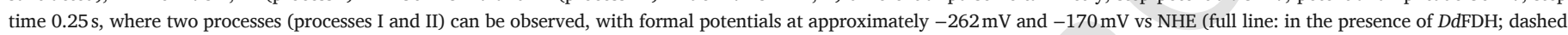
line: control in the absence of $D d F D H)$.
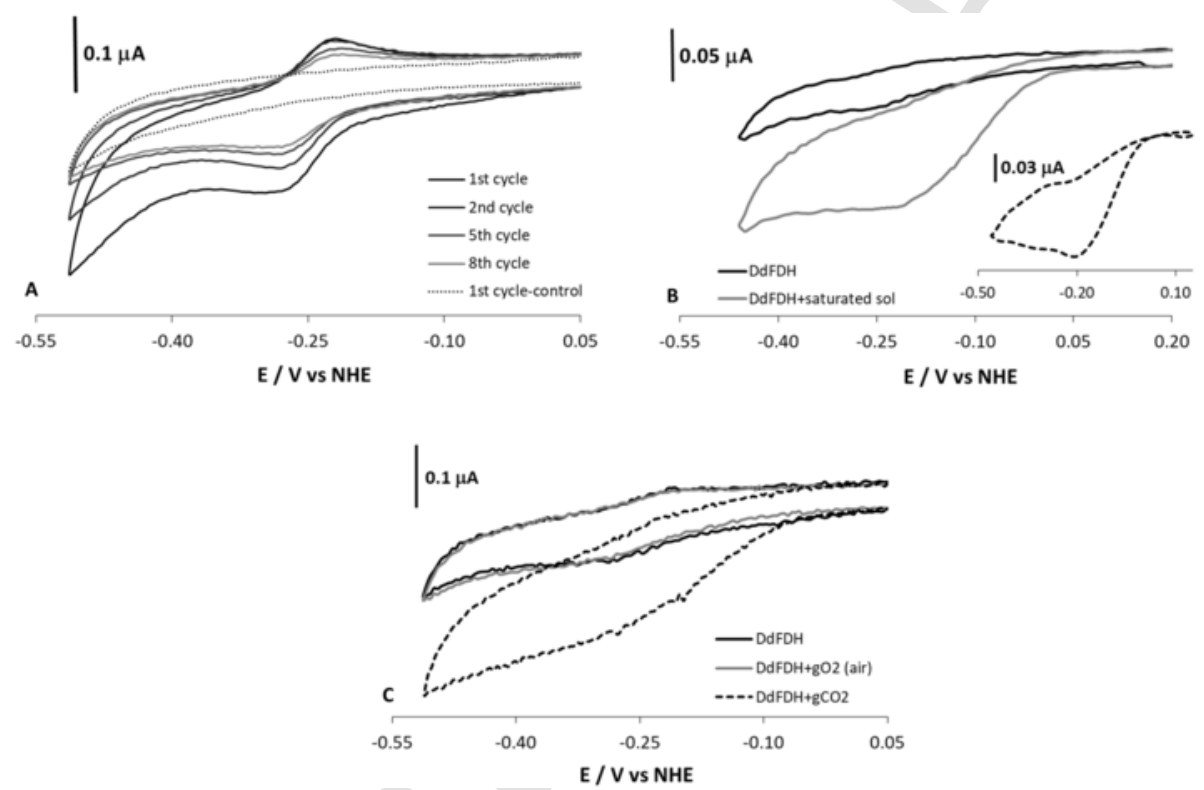

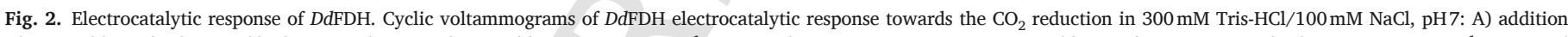

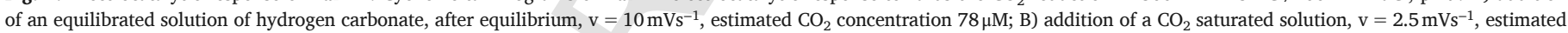
initial $\mathrm{CO}_{2}$ concentration $4.3 \mathrm{mM}$; C) direct $\mathrm{CO}_{2}$ injection in the electrochemical solution, $\mathrm{v}=10 \mathrm{mVs}^{-1}$, estimated initial $\mathrm{CO}_{2}$ concentration $1.6 \mathrm{mM}$.

from Desulfovibrio desulfuricans (DdFDH) is one of the most efficient carbon dioxide reducers so far described [7]. The enzyme has been demonstrated to possess high affinity for $\mathrm{CO}_{2}\left(K_{\mathrm{m}}{ }^{\text {app }}=15.7 \mu \mathrm{M}\right)$ and high rates for its reduction $\left(k_{\mathrm{cat}}{ }^{\mathrm{app}}=46.6 \mathrm{~s}^{-1}\right) . D d \mathrm{FDH}$ is a heterotrimeric enzyme, harbouring one molybdenum-containing active site, two [4Fe-4S] centres and four haems $c$. The molybdenum centre, in its oxidised form, harbours the molybdenum ion coordinated by the cis-dithiolene group of two pyranopterin molecules, one selenium from a selenium-cysteine residue and one terminal sulfur atom [23,24]. The other metallic redox-active centres, besides the Mo active site, have an electron transfer role, allowing the existence of an intramolecular electronic pathway from the physiological electron partner to the active site [25]. During catalysis, the molybdenum ion cycles between the Mo(VI) and Mo(IV) oxidation states and the formate oxidation/carbon dioxide reduction were recently suggested to proceed through hydride abstraction/insertion (respectively), with the terminal sulfido group of the molybdenum centre acting as the direct hydride acceptor $\left(\mathrm{Mo}^{(\mathrm{VI})}=\mathrm{S}\right) /$ donor $\left(\mathrm{Mo}^{(\mathrm{IV})}-\mathrm{SH}\right)$ (respectively) [7-11]. The two electrons (Eq. (1)) generated upon formate oxidation, or consumed during the carbon dioxide reduction are provided or accepted (respectively) by the physiological electron partner of each specific FDH enzyme. In vitro or in artificial systems, the electrons can be delivered/accepted by artificial electron donors/acceptors or by an electrode (as part of an electrochemical cell), via mediated or direct electron transfer $[17,19,26]$. Due to its unique kinetic parameters towards the carbon dioxide reduction [7], the $D d F D H$ is a good candidate to be incorporated in direct bioelectrochemical systems. Aiming to develop a future BES, in this work, we have characterised the $D d F D H$ electrochemical properties under non-turnover conditions, on pyrolytic graphite electrode, using direct electrochemical methods, without any mediators or surface modifiers. The electrochemical $D d F D H$ catalytic response towards the carbon dioxide reduction was also observed. The use of direct gaseous $\mathrm{CO}_{2}$ injection into the electrochemical cell was attempted resulting in observable catalytic currents, showing to be a viable methodology.

\section{Experimental}

\subsection{DdFDH purification and activity assessment}

The $D d F D H$ was purified as described before $[23,24]$. The as-purified enzyme purity was accessed by electrophoresis and UV-visible spectroscopy and its formate oxidase activity, found to be $201 \mu \mathrm{mol} /$ $\mathrm{min} / \mathrm{mg}$, was determined as described previously [23,24], following 


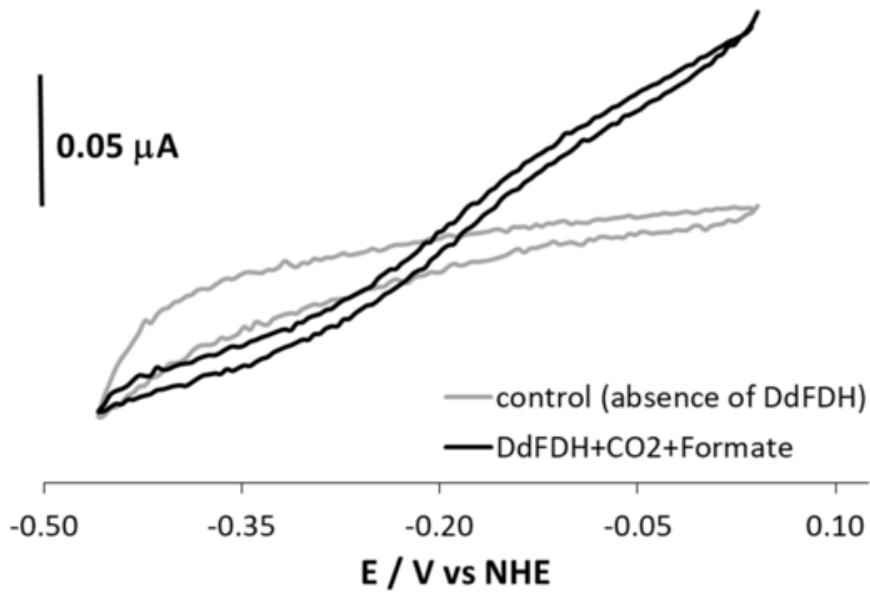

Fig. 3. Electrocatalytic response of $D d F D H$ in the presence of $\mathrm{CO}_{2}$ and formate. Representative cyclic voltammograms of the $D d F D H$ electrocatalytic response towards the $\mathrm{CO}_{2}$ reduction and formate oxidation, in $300 \mathrm{mM}$ Tris- $\mathrm{HCl} / 100 \mathrm{mM} \mathrm{NaCl}$, pH 7.6 when both substrates are present in solution, showing catalytic currents towards the $\mathrm{CO}_{2}$ reduction (cathodic currents) and formate oxidation (anodic currents); the initial concentrations were $5.2 \mathrm{mM}$ for $\mathrm{CO}_{2}$ (addition of a saturated $\mathrm{CO}_{2}$ solution) and $1.4 \mathrm{mM}$ of sodium formate; $\mathrm{v}=5 \mathrm{mVs}^{-1}$. The control was performed in the same electrolyte in the presence of both substrates (same concentrations and experimental conditions) but in the absence of the DdFDH.

spectrophotometrically the reduction of benzyl viologen at $555 \mathrm{~nm}$, in the presence of $10 \mathrm{mM}$ formate.

\subsection{Electrochemical methods}

Assays were performed using an AUTOLAB 30 potentiostat/galvanostat, on a three electrodes configuration, in a single compartment electrochemical cell, inside a Faraday cage. The working, secondary and reference electrodes were a pyrolytic graphite disk ( $2 \mathrm{~mm}$ diameter), a platinum wire and a saturated calomel electrode, with a potential of $+241 \mathrm{mV}$ versus the Normal Hydrogen Electrode (NHE), respectively. The working electrode was polished with two different grades of alumina ( 1 and $0.3 \mu \mathrm{m})$, subjected to a Millipore water ultra-sound bath for $2 \mathrm{~min}$, and washed thoroughly with Millipore water. After the electrode was dried, $5 \mu \mathrm{L}$ of the $D d F D H$ protein solution $(8 \mu \mathrm{M})$ were pipetted on top of the electrode. The protein solution was then entrapped using a cellulose membrane (spectra/Pro) with a $3.5 \mathrm{kDa}$ cut-off fitted with O-rings, as previously described [27], allowing the formation of a uniform protein thin layer on the electrode surface. Before starting the electrochemical assays, the electrolyte was degassed for a minimum $30 \mathrm{~min}$ using a continuous flow of argon. All the assays were performed in an anaerobic environment, at room temperature, with a positive pressure of argon maintained in the electrochemical cell headspace. The electrolyte used for the independent assays at $\mathrm{pH} 7$ was $300 \mathrm{mM}$ Tris- $\mathrm{HCl} /$ $100 \mathrm{mM} \mathrm{NaCl}$. The obtained reduction potential values were corrected for the NHE reference scale. The $\mathrm{CO}_{2}$ solubility in water $\left(1 \mathrm{~atm}, 25^{\circ} \mathrm{C}\right.$, Henry's law constant) was considered to be $34 \mathrm{mM}$ [28].

\section{Results and discussion}

\subsection{DdFDH direct electrochemical characterization}

The immobilized DdFDH direct electrochemical behaviour was observed by cyclic voltammetry (CV) and differential pulse voltammetry (DPV). Cyclic voltammograms show a well-defined redox couple (process I, see Fig. 1A), with formal potential, $\mathrm{E}^{0}=-250 \pm 8 \mathrm{mV}$ vs NHE, calculated by the midpoint of the anodic and cathodic potential peaks. Considering the experimental conditions, a good correlation was achieved for the $\mathrm{I}_{\mathrm{p}} \mathrm{vs} \mathrm{v}$ plots (up to $50 \mathrm{mV} \cdot \mathrm{s}^{-1}$ ) for this process I, consis- tent with a quasi-reversible system in a thin layer regime (thickness, $1 \approx 7 \mu \mathrm{m}$, considering a 2 electron process). In such experimental conditions, in which no diffusion of the electroactive species is considered, from the peak width at half height average values for process I (at least 10 replicates), the number of electrons involved was estimated to be 1.6, considered approximately as a two electron transfer (although not ideal behaviour). Using Laviron's mathematical approach [29], the heterogeneous electron transfer rate constant, $\mathrm{k}_{\mathrm{sh}}$, for process I, was then calculated to be $0.1 \mathrm{~s}^{-1}\left(10 \mathrm{mV} \cdot \mathrm{s}^{-1}\right.$, using $\left.\alpha=0.5\right)$. Taking in consideration the electrochemical behaviour of process I, including the values of the potentials obtained for catalytic currents (see below in the text), this was assigned to the redox transition $\mathrm{Mo}(\mathrm{VI} / \mathrm{IV})$ of the catalytic redox centre. The potential values observed seem in agreement with previous studies performed by EPR redox titrations (in different experimental conditions, namely temperature), where potential values of -330 and $-160 \mathrm{mV}$ were attributed to the redox couples $\mathrm{Mo}(\mathrm{V} / \mathrm{IV})$ and $\mathrm{Mo}(\mathrm{VI} / \mathrm{V})$, respectively [23] (in which the later couple is transient).

From the CV assays, a second redox couple can be identified (labelled as process III), in particular after the control subtraction (Fig. $1 \mathrm{~A}$ ), for which it was estimated a formal potential value, $\mathrm{E}^{0}$, of approximately $-99 \mathrm{mV}$ vs NHE. This redox couple is not so well-defined in the used experimental conditions and, as so, no other parameters for this process were calculated at this time. Using DPV two processes were also identified, a first process that should correspond to process I observed by $\mathrm{CV}$ with $\mathrm{E}^{0}=-262 \mathrm{mV}$ vs $\mathrm{NHE}$ and a second process (process II) at $-171 \mathrm{mV}$ vs NHE (Fig. 1B). The second process (process II) observed by DPV is far more negative than the second previously observed by $\mathrm{CV}$ (labelled process III), although is very close to the potential value of the couple $\mathrm{Mo}(\mathrm{VI} / \mathrm{V})$ found before $(-160 \mathrm{mV})$ [23]. Moreover, an estimation of the number of electrons associated with process I observed by DPV (through the peak width at half height, making an approximation to a reversible system $[30,31]$ ) was performed and resulted in $\mathrm{n} \approx 1.1$, which seems coherent with a one electron transfer process corresponding to the Mo(V/IV) couple. From the DPV measurements it was possible to differentiate two redox states of the molybdenum centre. It is not unusual that pulsed techniques (such as DPV) allow to discriminate reduction potentials that are observed by $\mathrm{CV}$ as overlapped signals (usually at low scan rates), in particular reactions involving transient/unstable species (such as Mo(V)), and/or species with close redox features, including enzymes with multiple centres [32-34]. Some studies on oxido-bisdithiolene inorganic models, similar to the molybdenum and tungsten centres of the FDH enzymes, have shown that is possible to discriminate the $\mathrm{Mo}(\mathrm{VI} / \mathrm{V})$ and $\mathrm{Mo}(\mathrm{V} / \mathrm{IV})$ reduction potentials. These models have formal potentials values around $-0.2 \mathrm{~V}$ vs $\mathrm{NHE}$ at $25^{\circ} \mathrm{C}$ [35]. Also, the models point to the more negative potential values for the $\mathrm{W}$ containing centres $[35,36]$, which is in agreement with the more negative catalytic potentials found for $\mathrm{W}$ containing enzymes, as discussed later.

\subsection{DdFDH electrocatalytic activity}

The electrocatalytic activity of $D d F D H$ towards the $\mathrm{CO}_{2}$ reduction was observed directly (without the presence of mediators) by cyclic voltammetry, through the addition of carbon dioxide by three different methods (Fig. 2), namely: a) addition of an equilibrated solution of sodium hydrogen carbonate, as previously described [7], b) addition of a saturated $\mathrm{CO}_{2}$ solution, previously prepared by continuous bubbling of $100 \%$ gaseous $\mathrm{CO}_{2}$ for $30 \mathrm{~min}$ and c) direct injection of gaseous $\mathrm{CO}_{2}$ into the electrolyte solution (in the electrochemical cell) and immediately starting the assays (in order that equilibrium between $\mathrm{CO}_{2} / \mathrm{CO}_{3}{ }^{-}$ in solution was not attained). All three methods have originated the increase of the cathodic current, with the maximum current observed around the potential of $-250 \mathrm{mV}$, where the first cycle is the one presenting the highest current, consistently diminishing in the subsequent 
cycles (see Fig. 2A). This behaviour is in agreement with previous reports of Mo and W-containing enzymes [19,20]. After multiple cycling (typically around 10 cycles), the catalytic current is no longer observed and the voltammogram features are similar to the ones obtained in non-turnover conditions, in the absence of any added substrate. The observed catalysis is electrochemically controlled, since no mediators are included in the electrolyte, and the reducing equivalents are provided directly by the electrode. To guarantee that the observed catalytic currents are due to the $D d F D H$-catalyzed $\mathrm{CO}_{2}$ reduction, different control assays were performed, namely, in the presence of $\mathrm{CO}_{2}$ but absence of the enzyme (Fig. 2A) and in presence of $D d F D H$ but with the addition of air instead of $\mathrm{CO}_{2}$ (Fig. 2C; an air-equilibrated solution contains only $13 \mu \mathrm{M}$ of carbon dioxide) where no significant current increase was detected. It is obvious that the results to be obtained using the third method are more difficult to control since gaseous $\mathrm{CO}_{2}$ is directly injected into the cell, but opens promising experimental possibilities to explore the process as part of a mitigation atmospheric system for the $\mathrm{CO}_{2}$ emissions, by using gas-diffusion type electrodes, as suggested by other studies [37].

In Fig. 2B, the Mo(VI)/Mo(IV) couple redox transition (process I), observed in the absence of $\mathrm{CO}_{2}$, presents a slight shift (around $20 \mathrm{mV}$ ) towards more positive potential values. The electrochemical behaviour of this couple, in these experimental conditions, was attained after the complete $\mathrm{CO}_{2}$ consumption, whose concentration in these assays was estimated to be, at the start of the experiment, $4.3 \mathrm{mM}$. The observed shift is related to the FDH catalytic activity and to the $\mathrm{CO}_{2}$ presence and is probably due to the acidification of the medium, as verified by other authors [20].

Complementary, another set of assays were performed where both formate and $\mathrm{CO}_{2}$ were simultaneously present in solution (Fig. 3), using the same experimental methodology described.

When both substrates are present, the individual features of the molybdenum redox centre are not observed. Instead, typical cathodic and anodic catalytic waves are observed, starting to develop around $-200 \mathrm{mV}$ (both in the cathodic and anodic directions), corresponding to $\mathrm{CO}_{2}$ reduction and formate oxidation, respectively, in a behaviour already described for other FDH enzymes $[19,20]$. Under these conditions, both observed catalytic currents increase with the applied overpotential, but a steady state is not clearly met (where a limiting current is reached), reflecting the high activity of the enzyme, and indicating the need of optimization of the imposed experimental conditions (namely the scan rate and the need to use a rotating electrode). The inflection point at approximately $-200 \mathrm{mV}$ seems to agree with the reduction potentials observed for the Mo centre in non-turnover conditions, as well as previous results obtained by EPR spectroscopy [23].

\section{Conclusions}

In this work we presented the direct electrochemical behaviour of the Mo containing formate dehydrogenase, purified from $D$. desulfuricans, where the Mo centre redox features were observed. The results allowed to calculate the reduction potentials associated with the couples Mo(VI/IV) (by CV) and Mo(VI/V) and Mo(V/IV) (by DPV). The catalytic currents associated with the carbon dioxide reduction were attained using direct cyclic voltammetry (without mediators) and different methodologies to add $\mathrm{CO}_{2}$ into the solution. When both $\mathrm{CO}_{2}$ and formate are present, the Mo centre redox features are not observed, but the development of characteristic sigmoidal catalytic currents towards the $\mathrm{CO}_{2}$ reduction and formate oxidation are observed. We believe that these qualitative results constitute a first step as a proof of concept that $D d F D H$ can be used as a basis for a BES device for the $\mathrm{CO}_{2}$ reduction, using gas-diffusion type electrodes, allowing the direct injection of atmospheric carbon dioxide and its reduction in situ.

\section{Abbreviations}

BES bioelectrochemical systems

$\mathrm{CV} \quad$ cyclic voltammetry

$\mathrm{CO}_{2} \quad$ carbon dioxide

Dd Desulfovibrio desulfuricans

DdFDH formate dehydrogenase isolated from Desulfovibrio desulfuricans

DPV differential pulse voltammetry

$\mathrm{HCOO}^{-}$formate

FDH formate dehydrogenase

$\mathrm{NADH}$ reduced nicotinamide adenine dinucleotide

\section{Acknowledgments}

This work was supported by the Associate Laboratory for Green Chemistry-LAQV, with national funds from FCT/MCTES (UID/QUI/ 50006/2019). "” LBM thanks to FCT/MCTES for the CEEC-Individual 2017 Program Contract.

\section{References}

[1] L. Maia, J. Moura, I. Moura, J. Biol. Inorg. Chem. 20 (2015) 287-309, (Springer Science \& Business Media B.V.).

[2] L.B. Maia, I. Moura, J.J.G. Moura, Inorg. Chim. Acta 455 (2017) 350-363.

[3] D. Niks, R. Hille, Protein Science, vol. 28, John Wiley \& Sons, Ltd, 2019111-122.

[4] R. Hille, J. Hall, P. Basu, Chem. Rev. 114 (2014) 3963-4038, (American Chemical Society).

[5] L.B. Maia, I. Moura, J.J.G. Moura, Molybdenum and Tungsten Enzymes: Biochemistry, The Royal Society of Chemistry, 20171-80.

[6] L.B. Maia, J.J.G. Moura, Reference Module in Chemistry, Molecular Sciences and Chemical Engineering, Elsevier, 2018.

[7] L.B. Maia, L. Fonseca, I. Moura, J.J.G. Moura, J. Am. Chem. Soc., vol. 138 (2016) 8834-8846, (American Chemical Society).

[8] D. Niks, J. Duvvuru, M. Escalona, R. Hille, J. Biol. Chem. 291 (2016) 1162-1174.

[9] X. Yu, D. Niks, A. Mulchandani, R. Hille, J. Biol. Chem. 292 (2017) 16872-16879.

[10] D. Niks, R. Hille, in: F. Armstrong (Ed.), Methods in Enzymology, vol. 613, Academic Press, 2018, pp. 277-295.

[11] G. Dong, U. Ryde, J. Biol. Inorg. Chem. (2018).

[12] R.F. Service, Science 349 (2015) 1158-1160.

[13] A.M. Appel, J.E. Bercaw, A.B. Bocarsly, H. Dobbek, D.L. DuBois, M. Dupuis, J.G. Ferry, E. Fujita, R. Hille, P.J.A. Kenis, C.A. Kerfeld, R.H. Morris, C.H.F. Peden, A.R. Portis, S.W. Ragsdale, T.B. Rauchfuss, J.N.H. Reek, L.C. Seefeldt, R.K. Thauer, G.L. Waldrop, Chemical Reviews, vol. 113, American Chemical Society, 20136621-6658.

[14] C. Finn, S. Schnittger, L.J. Yellowlees, J.B. Love, Chem Commun, vol. 48, The Royal Society of Chemistry, 20121392-1399.

[15] L. Zhang, J. Liu, J. Ong, S.F.Y. Li, Chemosphere 162 (2016) 228-234.

[16] S. Srikanth, M. Maesen, X. Dominguez-Benetton, K. Vanbroekhoven, D. Pant, Bioresour. Technol. 165 (2014) 350-354.

[17] K. Sakai, Y. Kitazumi, O. Shirai, K. Kano, Electrochem. Commun. 65 (2016) 31-34.

[18] M. Yuan, S. Sahin, R. Cai, S. Abdellaoui, D.P. Hickey, S.D. Minteer, R.D. Milton, Angewandte Chemie International Edition, vol. 57, Wiley-Blackwell, 20186582-6586.

[19] T. Reda, C.M. Plugge, N.J. Abram, J. Hirst, Proc. Natl. Acad. Sci. 105 (2008) 10654.

[20] A. Bassegoda, C. Madden, D.W. Wakerley, E. Reisner, J. Hirst, J. Am. Chem. Soc., vol. 136 (2014) 15473-15476, (American Chemical Society).

[21] M. Miller, W.E. Robinson, A.R. Oliveira, N. Heidary, N. Kornienko, J. Warnan, I.A.C. Pereira, E. Reisner, Angewandte Chemie, vol. 0, John Wiley \& Sons, Ltd, 2019.

[22] K.P. Sokol, W.E. Robinson, A.R. Oliveira, J. Warnan, M.M. Nowaczyk, A. Ruff, I.A.C. Pereira, E. Reisner, J. Am. Chem. Soc. 140 (2018) 16418-16422, (American Chemical Society).

[23] C. Costa, M. Teixeira, J. LeGall, J.J.G. Moura, I. Moura, J. Biol. Inorg. Chem. 2 (1997) 198-208.

[24] M.G. Rivas, P.J. González, C.D. Brondino, J.J.G. Moura, I. Moura, J. Inorg. Biochem. 101 (2007) 1617-1622.

[25] M. Jormakka, S. Törnroth, B. Byrne, S. Iwata, Science 295 (2002) 1863.

[26] K. Schuchmann, V. Müller, Science 342 (2013) 1382-1385.

[27] T.C. Santos, A.R. de Oliveira, J.M. Dantas, C.A. Salgueiro, C.M. Cordas, Biochim. Biophys. Acta Bioenerg. 1847 (2015) 1113-1118.

[28] R. Sander, Atmos. Chem. Phys. 15 (2015) 4399-4981.

[29] E. Laviron, J. Electroanal. Chem. Interfacial Electrochem. 101 (1979) 19-28.

[30] A.M.O. Brett, C.M.A. Brett, Journal (1993), (Pages).

[31] M.M. Correia dos Santos, P.M. Paes de Sousa, M.L. Simões Gonçalves, L. Krippahl, J.J.G. Moura, É. Lojou, P. Bianco, J. Electroanal. Chem. 541 (2003) 153-162.

[32] F. Folgosa, C.M. Cordas, J.A. Santos, A.S. Pereira, J.J.G. Moura, P. Tavares, I. Moura, Biochem. J. 438 (2011) 485-494.

[33] Z. Guo-hua, L. Ming-fang, L. Ming-li, Cent. Eur. J. Chem. 5 (2007) 1114-1123. 
[34] C. Moreno, A. Campos, M. Teixeira, J. LeGall, M.I. Montenegro, I. Moura, C. Dijk, J.G.J. Moura, Eur. J. Biochem. 202 (1991) 385-393, (Wiley/Blackwell (10.1111)).

[35] C. Schulzke, Dalton Trans. (2005) 713-720, (The Royal Society of Chemistry).
[36] H. Sugimoto, K. Sugimoto, Inorg. Chem. Commun. 11 (2008) 77-80.

[37] K. Sakai, Y. Kitazumi, O. Shirai, K. Takagi, K. Kano, Electrochem. Commun. 73 (2016) 85-88. 